\title{
Combinando Colgajos en reconstrucción facial, colgajo de Mustardé y colgajo paramediano frontal para reconstrucción de mejilla y ala nasal a propósito de un caso.
}

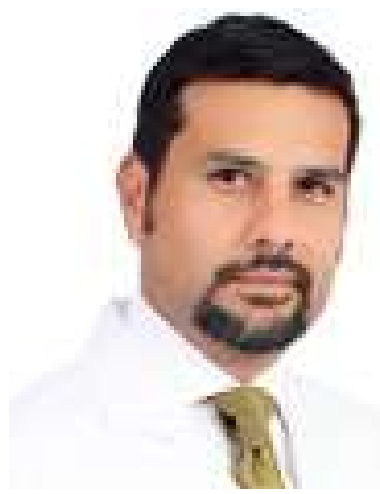

\author{
Dr. Raúl A. Escobar Ugarte \\ Cirujano Plástico Estético y Reconstructivo Instituto Oncológico del Oriente Boliviano \\ Miembro titular SBCPER SCCPRE \\ e-mail: rauladrianescobar@icloud.com
}

\section{"Combining flaps in facial reconstruction; Mustardé flap and forehead flap for reconstruction of cheek and nose, A case report."}

\section{RESUMEN}

Está ampliamente descrito en la literatura el uso de múltiples colgajos aplicados a defectos que abarcan más de una subunidad facial, cuando éstos demandan un reto reconstructivo para el cirujano. La resección de un carcinoma basocelular que afecta la mejilla y el espesor completo del ala nasal causa un defecto significativo. Cuando un colgajo único, no es suficiente para aportar el tejido necesario para restaurar la función, se pueden diseñar varios colgajos en un mismo tiempo quirúrgico que permita lograr nuestro objetivo principal: restaurar la función con la mejor apariencia cosmética posterior.

Presentamos a continuación, un caso resuelto con la combinación de 2 colgajos para reconstruir un defecto combinado de mejilla y ala nasal de espesor completo en el instituto Oncológico del Oriente Boliviano. Como resultado obtuvimos una aceptable apariencia cosmética final, con restauración funcional de las subunidades afectadas por las lesiones originales y una morbilidad mínima de la zona donante en la región frontal.

\section{SUMMARY}

The use of multiple flaps applied to defects that cover more than one facial subunit when they demand a reconstructive cha- llenge for the surgeon is widely described in the literature. The resection of a basal cell carcinoma affecting the cheek and the complete thickness of the nasal ala causes a significant defect. When a single flap is not enough to provide the tissue necessary to restore function, several flaps can be designed in the same surgical time to achieve our main objective of restoring function with the best cosmetic appearance.

We present a case resolved with the combination of 2 flaps to reconstruct a combined defect of cheek and full thickness nasal Ala at the Oncological Institute on the Eastern part of Bolivia.

As a result, we obtained an acceptable final cosmetic appearance with functional restoration of the subunits affected by the original lesions and minimal morbidity of the donor area in the forehead region.

\section{PALABRAS CLAVE}

Colgajo de Mustardé, Colgajo Paramediano Frontal, Reconstrucción de mejilla, Reconstrucción de ala nasal, reporte de caso.

\section{KEY WORDS}

Mustardé Flap, Forehead Flap, cheek reconstruction, nasal ala reconstruction, case report. 


\section{OBJETIVO}

Describir el uso de la combinación de colgajos en reconstrucción facial en defectos complejos que abarcan 20 más subunidades faciales en paciente portador de carcinoma basocelular en mejilla y ala nasal en el Instituto Oncológico del Oriente boliviano.

\section{MÉTODO}

Se realiza la reconstrucción de 2 defectos que abarcan la zona limítrofe entre la mejilla y la vertiente nasal derecha, y otro defecto de espesor completo que involucra el ala nasal derecha respectivamente. Utilizamos un colgajo de rotación de Mejilla y un colgajo paramediano frontal en 2 tiempos sobre un armazón de cartílago auricular, como área donante para cobertura externa y un colgajo de mucosa septal para cobertura interna.

\section{RESULTADO}

Se logró restaurar la funcionalidad nasal con una aceptable apariencia cosmética y una mínima morbilidad de la zona donante.

\section{CONCLUSIÓN}

El uso combinado de colgajos en reconstrucción facial por cáncer de piel permite abordar defectos complejos y múltiples que afectan a varias subunidades con resultados aceptables tanto funcionales como cosméticos.

\section{INTRODUCCIÓN}

Para la reconstrucción nasal, los puntos a considerar al elegir una opción reconstructiva incluyen el tamaño y la profundidad del defecto y el color y la textura de la piel nasal del paciente. Las subunidades estéticas también deben considerarse para obtener mejores resultados.

Mientras que las subunidades estéticas para la reconstrucción nasal fueron redifinidas por Burget y Menick(1), el ala nasal es estructura nasal crítica de alto valor estético. Por lo tanto, un defecto alar total de grosor completo es una deformidad desafiante, y se han reportado varias opciones de reparación (2).

De estos, el colgajo paramediano frontal puede proporcionar una nariz reconstruida de apariencia mas natural (1) (2) (5). Además, muchos autores han adoptado el principio de la subunidad y han insistido en agregar tejido de soporte de otra fuente, como el cartílago septal y / o el cartílago auricular, para mantener la simetría de la estructura alar postoperatoria.
En lugar de aplicar diferentes combinaciones de opciones reconstructivas, como el cierre parcial del defecto restante cerrando por segunda intención, utilizar parte del tejido amputado y colocarlo como injerto adyacente de grosor completo, colgajos de avance bipediculado con injerto de grosor dividido en sitios donadores no cerrados (5).

La combinación de dos o más de colgajos para lograr la cobertura necesaria sin una tensión excesiva y la distorsión resultante es el objetivo de este artículo (1)(2).

Los defectos que involucran múltiples subunidades faciales a menudo requieren una evaluación dinámica de la forma facial para restaurar el tejido cutáneo perdido (8).

Cualquier distorsión de la anatomía normal de la nariz es conspicua porque la nariz, junto con los labios y los ojos, son un punto de fijación visual en la identificación y apreciación estética del rostro (10).

La base nasal se divide medialmente en la ventana nasal y la base alar lateralmente, y está compuesta de tejido glandular fibroadiposo, que varía en grosor entre los pacientes debido a sus condiciones raciales.

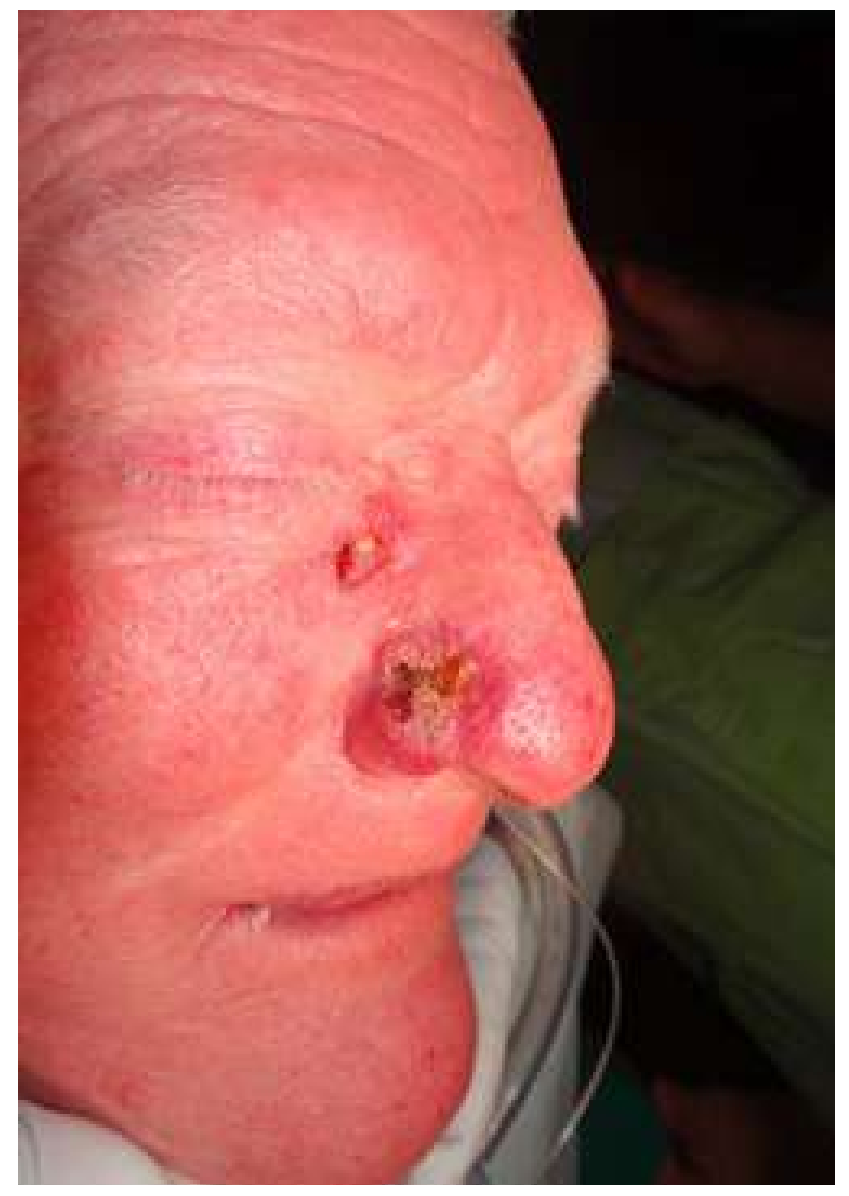

Figura 1. Visión lateral de las lesiones en mejilla y ala nasal derecha 


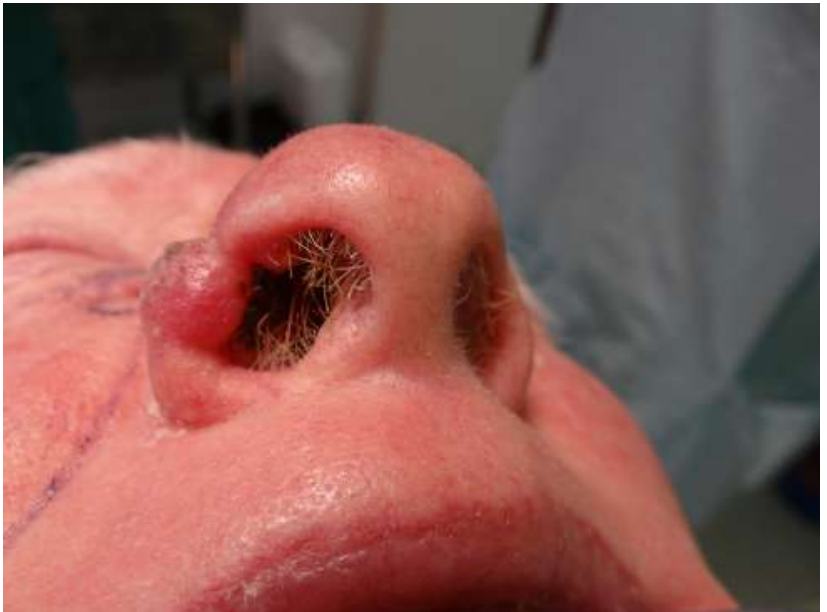

Figura 2. Vista nasal de la lesión en ala nasal derecha.

Los defectos de espesor total de toda el ala nasal, incluido el borde libre, pueden ser difíciles de reconstruir (5). Un colgajo paramediano puede proporcionar un ala nasal reconstruida cosmeticamente más natural. El revestimiento nasal interno se reconstruyó utilizando colgajo de mucosa septal (6).

Otra opción reconstructiva externa para un defecto alar entero completo puede ser un colgajo nasogeniano (10). Un colgajo nasogeniano solo, que puede transferirse fácilmente debido a su adyacencia al sitio receptor, es demasiado frágil para mantener la estructura del ala nasal. (2) Un colgajo nasogeniano sin soporte de cartílago por lo general queda insuficiente generando cierta asimetría comparada con el lado contralateral.

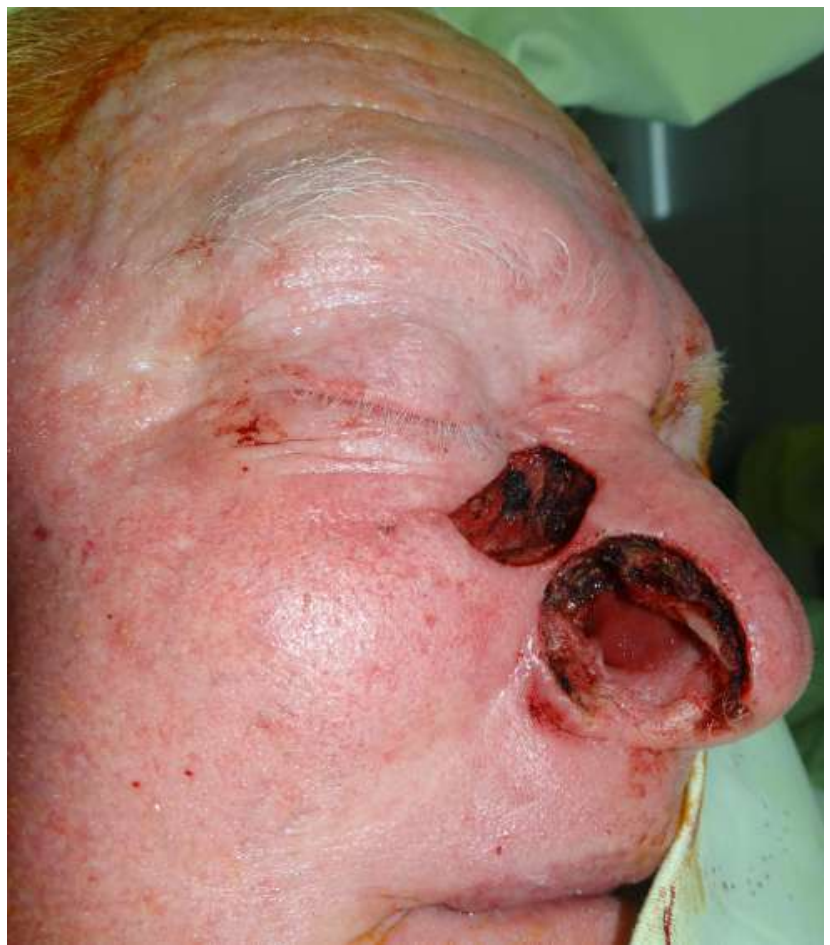

Figura 3. Vista lateral de la resección de las lesiones con márgenes de seguridad.

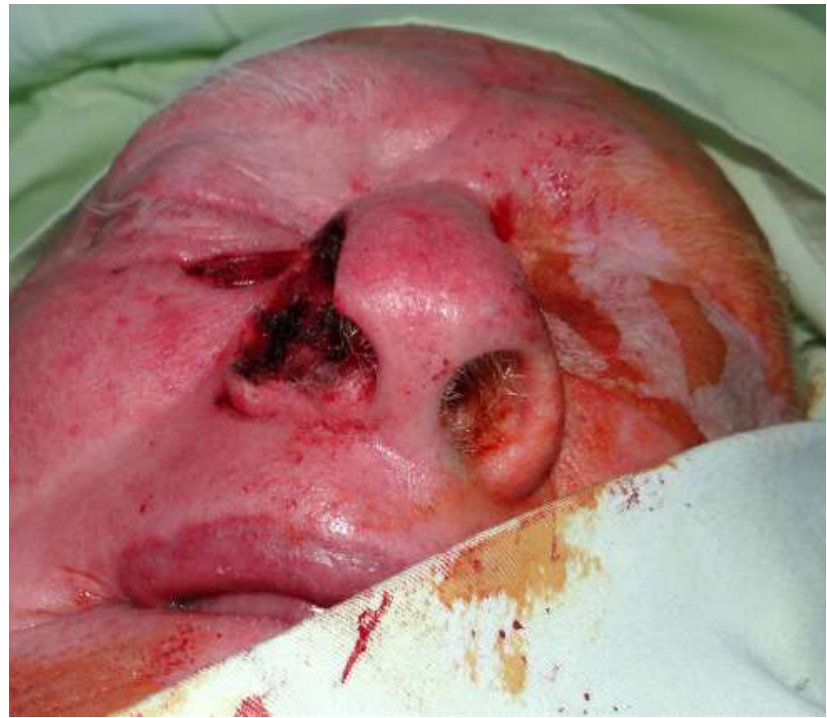

Figura 4. vista basal del defecto residual del ala nasal

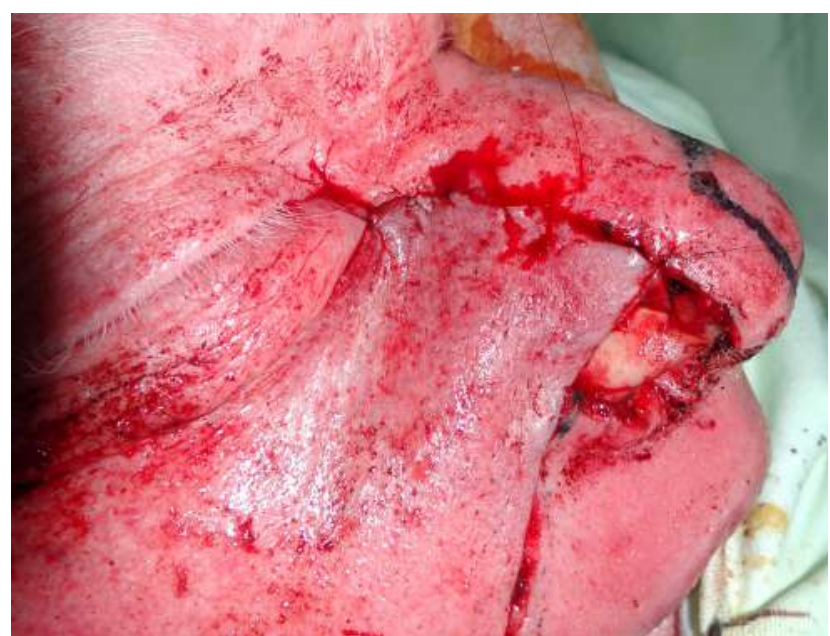

Figura 5. Colgajo de mejilla en posición y armazón cartilaginoso de soporte del ala nasal

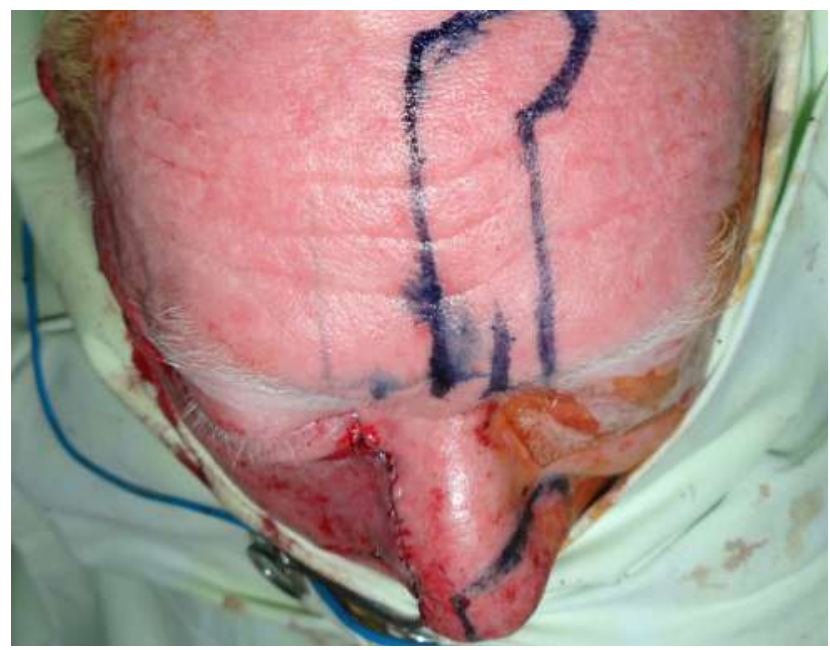

Figura 6. Diseño del colgajo frontal para cobertura externa del ala nasal 


\section{TÉCNICA QUIRÚRGICA}

La reconstrucción se realizó utilizando un colgajo frontal en 2 etapas. Para un enfoque cuidadoso se realizó paso a paso la reconstrucción, tanto intranasal como las porciones extranasales del defecto. Mientras que el sitio de la herida se reduce después de la escisión y se vuelve más pequeño que su tamaño original en el momento de la reconstrucción, el patrón exacto del defecto original debe diseñarse tomando en cuenta el lado contralateral. Se debe diseñar un molde previo.

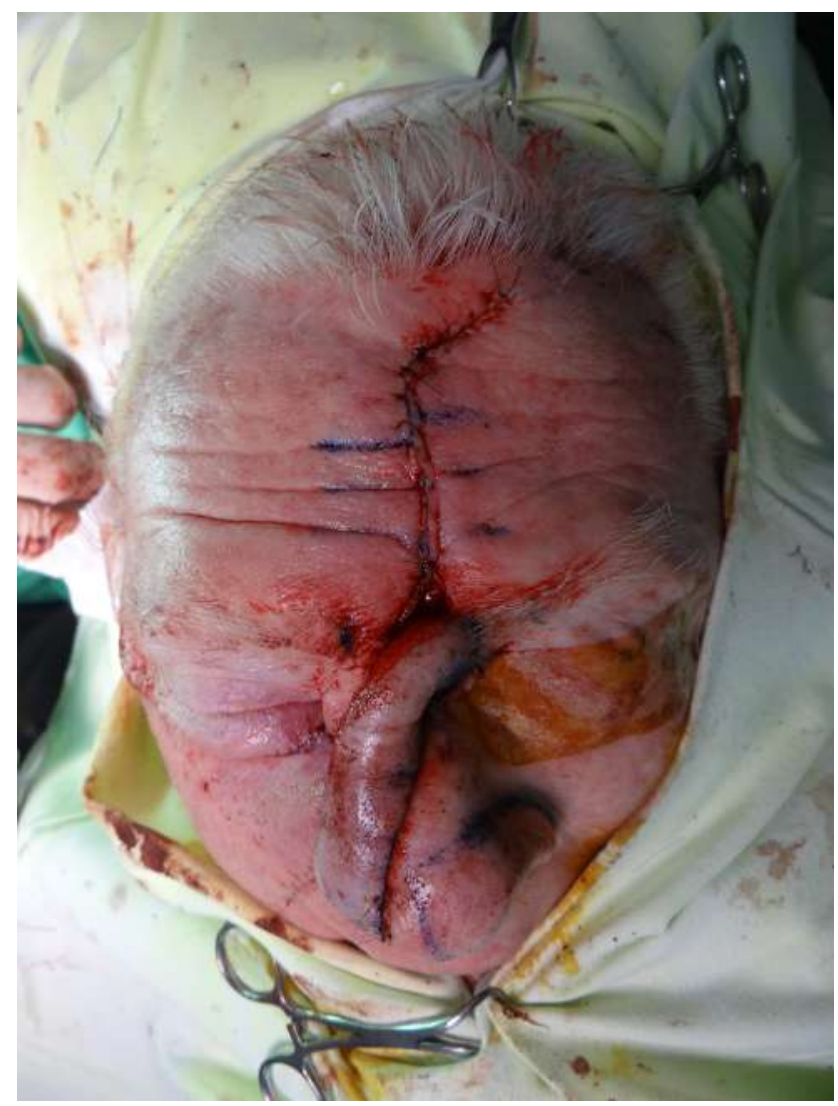

Figura 7. Colgajo frontal en posición

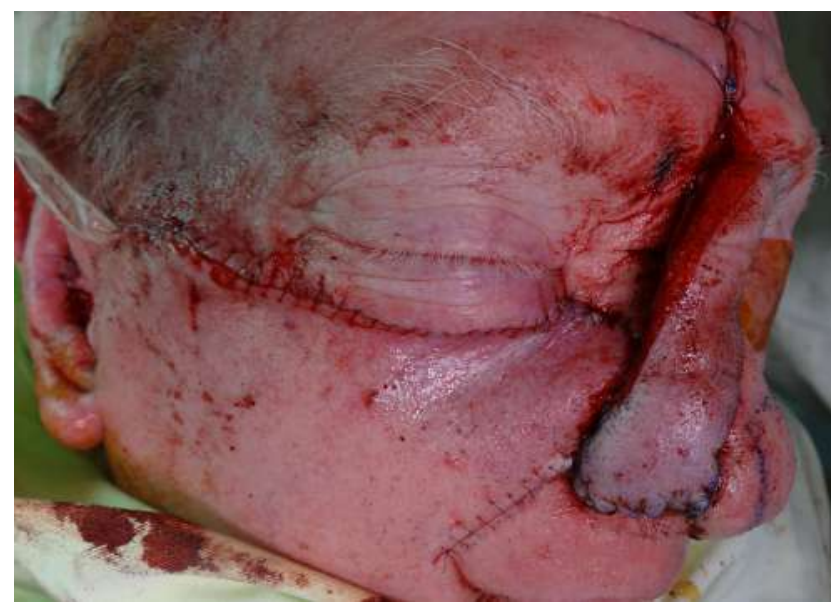

Figura 8. Vista lateral de la reconstrucción alar con el colgajo frontal
El área distal del colgajo debe coincidir con el defecto. El triángulo blando alar debe cubrirse con la piel del extremo del colgajo. No realizamos evaluación preoperatoria en los colgajos frontales, el único reparo que tomamos es que el paciente no tenga cicatrices previas que amenacen el pedículo de nuestro colgajo. El colgajo completo se eleva justo por encima del periostio, y el área distal planeada para cubrir el defecto se usa sin adelgazamiento. El área donante que utilizamos para el revestimiento intranasal fue proporcionada por un colgajo de mucosa septal de base anteroinferior. Después de la cobertura interna, el colgajo frontal se insertó y se suturó en la nariz.

Luego de 3 semanas se realizó el segundo tiempo. Simultáneamente se diseño un colgajo de rotación de mejilla tipo Mustardé para lograr la reconstrucción de la subunidad de la mejilla en el mismo tiempo quirúrgico.

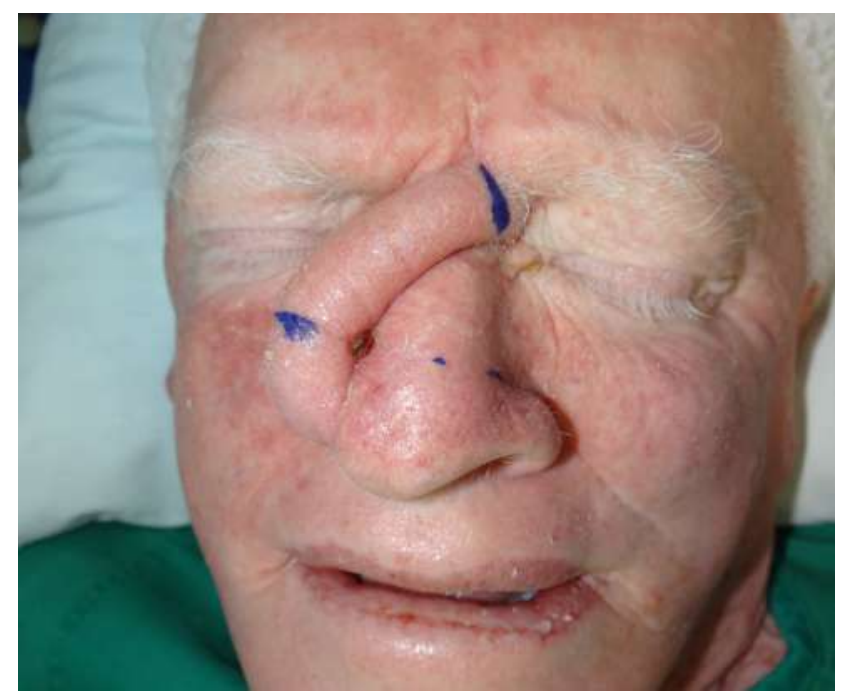

Figura 9. Colgajo frontal luego de 3 semanas listo para división

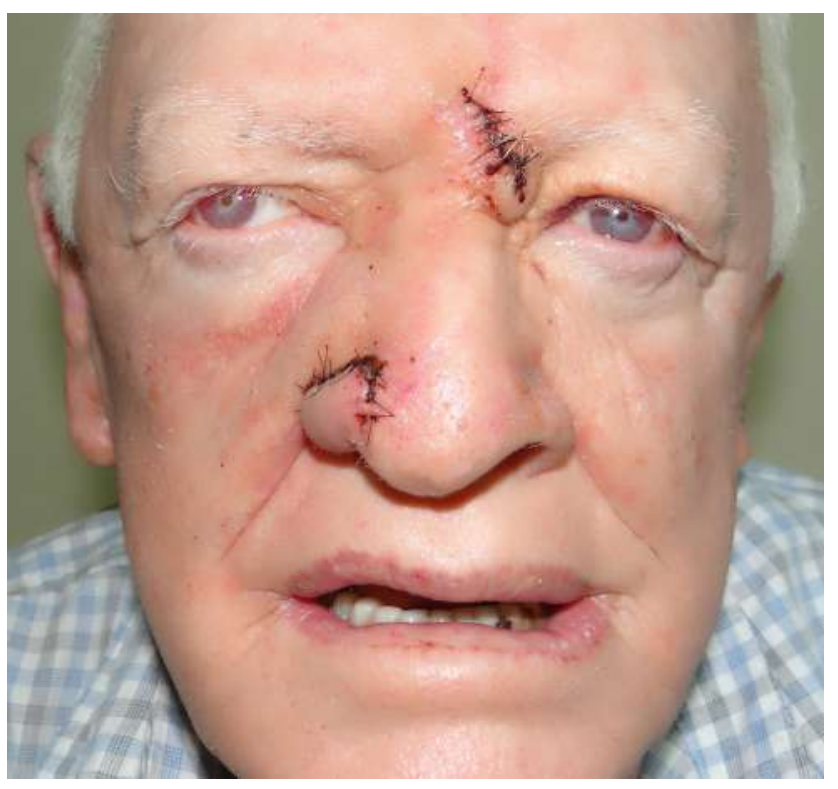

Figura 10. Vista posterior a división del pedículo del colgajo frontal 


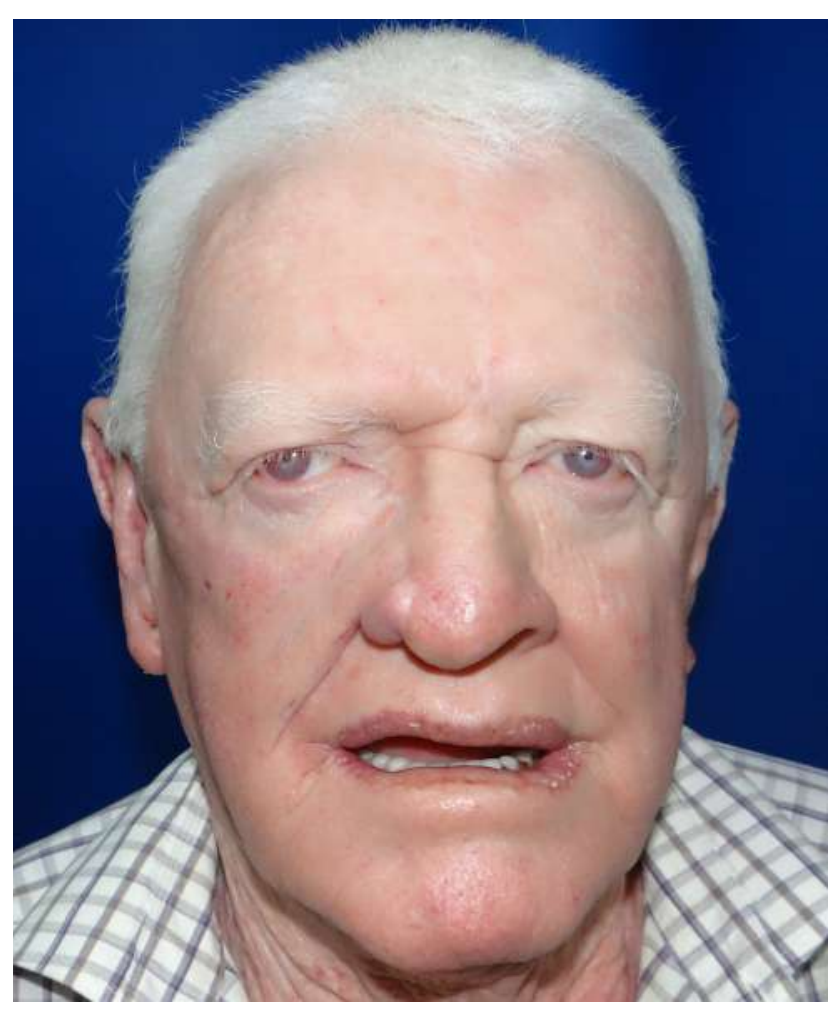

Figura 11. Vista frontal con 2 meses postoperatorio

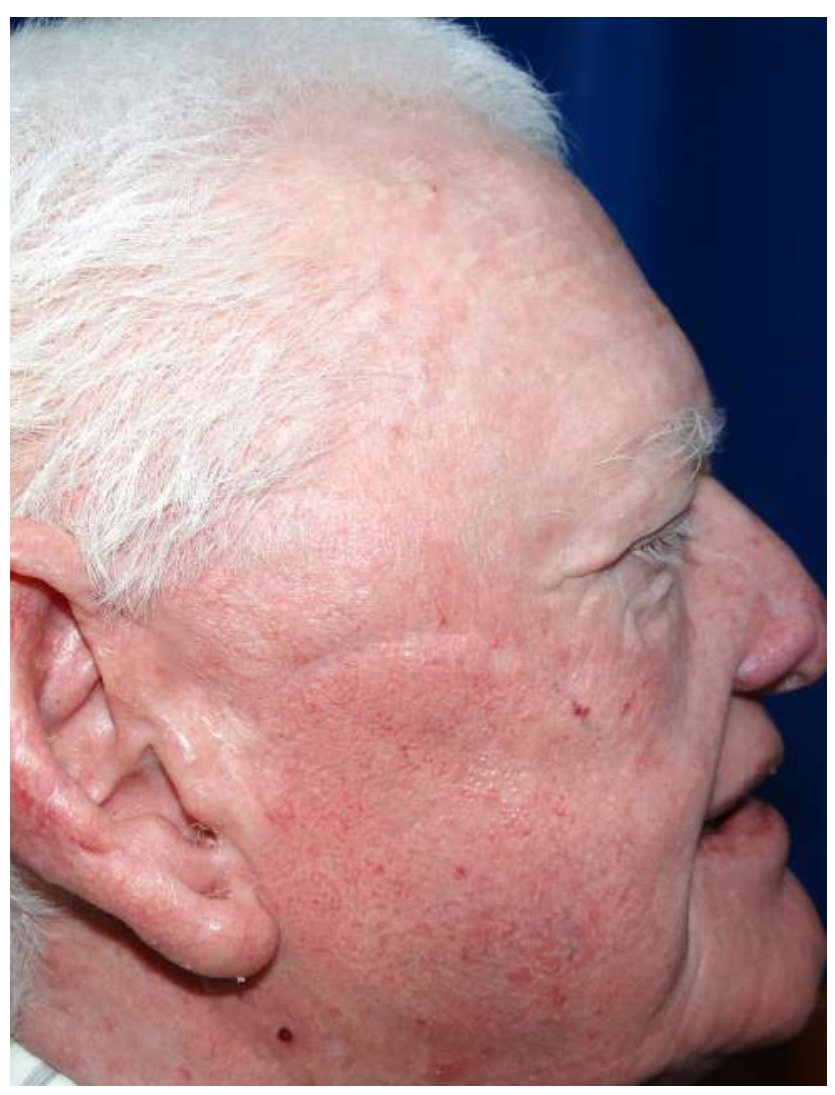

Figura 12. vista lateral mostrando un resultado cosmético satisfactorio ista lateral mostrando un resultado cosmético satisfactorio

\section{DISCUSIÓN}

El ala nasal es una importante subunidad nasal cosmética y funcional, con un surco alar que proporciona una señal visual para separar esta estructura del resto de las subunidades cosméticas de la nariz. La reconstrucción de defectos, incluido el ala nasal completa, puede ser difícil de planificar y ejecutar. Como se mencionó anteriormente, el "principio de la subunidad nasal" ha demostrado ser muy útil a la hora de planear la reconstrucción.

\section{CONCLUSIONES}

El grosory la compatibilidad de la piel de la frente para restaurar la forma alar nasal en los pacientes nos da un resultado alentador, el ala nasal reconstruida coincide con el color original de la piel y mantiene una forma apropiada. El resultado cosmético final restaurando las subunidades afectadas nos proporciona un soporte para continuar la reconstrucción facial combinando colgajos en un mismo tiempo quirúrgico.

\section{BIBLIOGRAFÍA}

1.- Burget GC, Menick FJ. The subunit principle in nasal reconstruction. Plast Reconstr Surg 1985;76:239-247

2.- Burget GC, Menick FJ. Nasal support and lining: the marriage of beauty and blood supply. Plast Reconstr Surg 1989;84:189-203

3.- Zhang YX, Yang J, Wang D, et al. Extended application of vascularized preauricular and helical rim flaps in reconstruction of nasal defects. Plast Reconstr Surg 2008;121:1589-1597

4.- Qian C, Yaodong X, Xiaoming H, et al. Repair of full-thickness alar defects. Dermatol Surg 2012;38:1639-1644

5.- Menick FJ. A 10-year experience in nasal reconstruction with the three- stage forehead flap. Plast Reconstr Surg 2002;109:1839-1855

6.- Brodland DG. Paramedian forehead flap reconstruction for nasal defect. Dermatol Surg 2005;31:1046-1052

7.- Burget GC, Menick F). Aesthetic Reconstruction of the Nose.

St Louis, MO: Mosby Year Book; 1994

8.- Terashi $\mathrm{H}$, Kurata $\mathrm{S}$, Hashimoto $\mathrm{H}$, et al. Adequate depth of excision for basal cell carcinoma of the nose. Ann Plast Surg 2002;48:214-216

9.- Rohrich RJ, Barton FE, Hollier L. Nasal reconstruction. In: Aston SJ, Beasley RW, Thorne CHM, eds. Grabb and Smith's Plastic Surgery. 5th ed. Boston, MA: Little Brown; 1997:513-528

10.- Menick FJ. Nazal reconstruction with a forehead flap. Clin Plast Surg 2009;36:443-459 